\title{
Occurrence of blood-feeding terrestrial leeches (Haemadipsidae) in a degraded forest ecosystem and their potential as ecological indicators
}

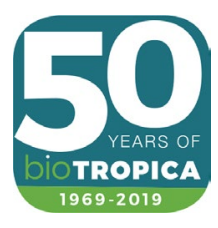

\author{
Rosie Drinkwater $^{1}$ (D) | Joseph Williamson ${ }^{1}$ (D) | Tom Swinfield ${ }^{2}$ (D) | Nicolas J. Deere ${ }^{3}$ (D) | \\ Matthew J. Struebig ${ }^{3}$ (D) | Elizabeth L. Clare ${ }^{1}$ (D) | David Coomes ${ }^{2}$ | Stephen J. Rossiter ${ }^{1}$ (D)
}

${ }^{1}$ School of Biological and Chemical Sciences, Queen Mary University of London, London, UK

${ }^{2}$ Department of Plant Sciences, University of Cambridge, Cambridge, UK

${ }^{3}$ School of Anthropology and Conservation, University of Kent,

Canterbury, UK

\section{Correspondence}

Rosie Drinkwater, School of Biological and Chemical Sciences, Queen Mary University of London, London, UK.

Email:r.drinkwater@qmul.ac.uk

Funding information

Natural Environment Research Council, Grant/Award Number: NE/K016148/1

Associate Editor: Emilio Bruna

Handling Editor: Alexander Lees

\begin{abstract}
Blood-feeding invertebrates are emerging model taxa in biodiversity assessments, both as indicators of mammal abundance and also as sources of mammal DNA for identification. Among these, terrestrial leeches arguably offer the greatest promise; they are abundant and widespread in the humid tropics, and their blood meals can be easily assayed to establish diet. Unfortunately, terrestrial leeches are understudied, with little known about their ecology and behavior. Such information is needed to evaluate their utility as ecological indicators and to account for potential sampling biases that might arise from habitat preferences. By combining occupancy modeling and thermal tolerance assays, we determined the factors affecting species occurrence in the related terrestrial brown (Haemadipsa sumatrana) and tiger leech (Haemadipsa picta), both of which are widespread in tropical forests in Southeast Asia. We sampled both species across a degraded forest landscape in Sabah, Borneo, in wet and dry seasons, associating occurrence with habitat-level metrics. We found that, for both species, detection probability increased with canopy height regardless of season. Additionally, increased vegetation heterogeneity had a strong negative influence on brown leech occurrence in the dry season, implying an interaction between vegetation structure and climate. However, we found no difference in physiological thermal tolerance ( $\mathrm{CT}_{\text {MAX }}$ ) between the two species. Finally, using a reduced dataset, we found a small improvement in brown leech model fit when including mammal abundance. Our results suggest that the presence of terrestrial leeches may act as useful ecological indicators of habitat quality and potentially mammalian abundance.

Abstract in Indonesia is available with online material.
\end{abstract}

\section{KEYWORDS}

Borneo, Haemadipsidae, human-modified forest, indicators, occupancy modeling, thermal tolerance

This is an open access article under the terms of the Creative Commons Attribution License, which permits use, distribution and reproduction in any medium, 


\section{1 | INTRODUCTION}

Hematophagous (blood-feeding) invertebrates are emerging model taxa in biodiversity assessments. Due to their dietary habits, they might serve as useful bioindicators of mammal abundance. Additionally, they are increasingly used in molecular ecology as sources of mammal DNA for identification. Of all the blood-feeding invertebrates, terrestrial leeches from the Haemadipsidae family perhaps offer the most promise as bioindicators (Calvignac-Spencer, Leendertz, Gilbert \& Schubert, 2013). These leeches number 70 species and, along with aquatic forms, belong to the order of jawed leeches (Hirudiniformes). In freshwater systems, in Europe and North America, aquatic leeches have been used as indicators of environmental stressors such as dissolved oxygen (Cortelezzi et al., 2018) and pollutants (de Campos Brites \& Rantin, 2004), and their tissues can be examined to detect agricultural contaminants (Scrimgeour, Wicklum \& Pruss, 1998). Freshwater leech egg-cocoons have even been suggested as useful paleolimnological indicators for submerged macrophytes in European lakes (Vad Odgaard \& Rasmussen, 2001). Terrestrial haemadipsid leeches might also provide information on multiple aspects of ecosystem health, with previous work indicating that these taxa are influenced by vegetation cover in forest (Kendall, 2012) and plantations (Tan, Qian, Zhang \& Chen, 1989). Indeed, these leeches are likely to be highly sensitive to processes that lead to structural changes in vegetation such as logging and fragmentation (Fogden \& Proctor, 1985), probably mediated through associated alteration to microclimate. Moreover, aside from the utility of haemadipsid leeches as ecological indicators, their direct dependence on vertebrate taxa means that they might, in theory, also be useful biodiversity indicators. Such claims have been made for dung beetles due to their reliance on mammal feces, and several studies have suggested that dung beetle abundance and diversity decline with the hunting of mammals (Andresen \& Laurance, 2006; Nichols, Gardner, Peres \& Spector, 2009).

There is also growing interest in blood-feeding leeches as socalled "vertebrate samplers" in molecular studies of invertebratederived DNA (iDNA). Briefly, iDNA approaches quantify vertebrate diversity through the sequencing of invertebrate blood meals, typically recovered from groups such as mosquitoes, terrestrial leeches, or carrion flies (Calvignac-Spencer, Merkel, et al., 2013; Kocher et al., 2017; Schnell et al., 2012). Comparative analyses of haemadipsid leeches sampled from across their global range have indicated that they exhibit generalist diets, featuring multiple vertebrate groups (Schnell et al., 2018; Tessler et al., 2018) although studies at a finer resolution have detected interspecific and site-specific feeding differences in Bornean (Drinkwater et al., 2018) and Madagascan haemadipsid species (Fahmy, Ravelomanantsoa, Youssef, Hekkala \& Siddall, 2019). Several studies have also compared the effectiveness of invertebrate samples against other biodiversity monitoring techniques, such as camera traps (Lee, Gan, Clements, Wilson \& Adamowicz, 2016; Weiskopf et al., 2017). However, iDNA studies to date-of leeches and other groups-have not examined the habitat preferences of the invertebrates themselves, which could result in ascertainment biases and thus limit their usefulness as samplers.

Although Hirudiniformes leeches are likely to play important roles in ecosystems, both as prey and as predatory parasites, very little is known about their general ecology and behavior (Sawyer, 1986). Terrestrial species are mainly restricted to wet and humid ecosystems, where they are often abundant and widespread (Sket \& Trontelj, 2008). As a group, the three-jawed (trignathous) haemadipsid leeches, containing members of the relatively speciose Haemadipsa (24 species), are generally abundant and found in South and Southeast Asia (Borda \& Siddall, 2010). In contrast, the two-jawed (duognathous) leeches, Chtonobdella spp, have more restricted distributions, in Australia, Madagascar, Indonesia, and several South Pacific islands (Tessler et al., 2016).

In this study, we set out to examine the ecological determinants of leech distributions in Southeast Asian forests, focusing on two species: Haemadipsa sumatrana (brown leech) and Haemadipsa picta (tiger leech). These have distinct morphological and behavioral characteristics that allow their separation in the field (Figure 1). Previous work in Borneo has suggested that the tiger leech favors degraded forest habitat (i.e., encounter rate increases with declining forest quality), whereas the brown leech favors intact forest habitats (Kendall, 2012), and a similar difference in microhabitat use was shown along trails in primary forest, with the tiger leech more commonly found at the edges of trails, and above ground level, than the brown leech (Gąsiorek \& Różycka, 2017). The brown leech has a more specialized habitat, in the leaf litter compared to the tiger leech (Gąsiorek \& Różycka, 2017). These differences in tolerance to disturbed habitats demonstrate a potential for the use of these species as ecological indicators. To better understand how these two species are distributed throughout the landscape, we use a single-season occupancy approach. Occupancy models can be used to account for the inherent imperfect detection of any ecological sampling technique (MacKenzie et al., 2002). These models are highly versatile and allow the inference of species occurrence in a landscape using detection/ non-detection data from repeated surveys at multiple sites (Bailey, Mackenzie \& Nichols, 2014). Species occupancy can be defined as the probability a sampling unit (site) is occupied or used by the species during a sampling season (Bailey et al., 2014). Detection probability, on the other hand, is a measure of the observation error during a given survey, which equates to the probability of detecting a species, given that it occurs at the site. Environmental covariates can also be included in the models, allowing occupancy and detection probability to vary with site- and survey-specific differences (MacKenzie et al., 2002), making this a good approach for understanding species occurrences across spatial gradients. We had two main aims: first, to gain a deeper understanding of the distribution of the sympatric brown ( $H$. sumatrana) and tiger ( $H$. picta) leech, we modeled species occupancy and detection probability across a land-use gradient. As terrestrial leeches are restricted to humid and wet habitats, we carried out surveys in 
both wet and dry seasons to investigate any seasonal differences in the distribution of the two species. Secondly, to elucidate the underlying mechanisms determining distribution patterns we tested interspecific differences in physiological thermal tolerance for the two focal taxa.

\section{2 | METHODS}

\subsection{Field site and leech surveys}

To analyze how forest structure influences the distribution of the two sympatric terrestrial leech types, we surveyed sites across a gradient of habitat quality. Our naming of the two leech species follows (Borda, Oceguera-Figueroa \& Siddall, 2008; Schnell et al., 2018; Tessler et al., 2018), but we recognize that genetic relationships among leeches are not always well resolved, and it is possible that some taxa might in time become recognized as species complexes (Borda et al., 2008; Schnell et al., 2018; Tessler et al., 2018). The surveys were conducted at the Stability of Altered Forest Ecosystems Project (SAFE project), a 72,000 ha fragmentation experiment in Sabah, Malaysian Borneo $\left(4^{\circ} 33^{\prime} \mathrm{N}, 117^{\circ} 16^{\prime} \mathrm{E}\right)$ (Ewers et al., 2011). Surveys were conducted during the dry season and drought associated with a particularly severe El Niño event (March-June 2015) (Timmermann et al., 2018). The second set of surveys was conducted during a more typical rainy season (September-December 2016). During each of these periods, we made four repeated surveys at 179 of the long-term vegetation plots at the SAFE project. These vegetation plots are $25 \mathrm{~m}^{2}$ and are spaced at least $174 \mathrm{~m}$ apart; they fall within broadly different land-use histories including once-logged, twice-logged, heavily logged, clear-felled forest, riparian forest corridors, and oil palm plantation habitats (Figure S1). Due to the habitat restrictions of terrestrial leeches, oil palm plots were not surveyed (Fogden \&
Proctor, 1985; Kendall, 2012) (Fogden \& Proctor, 1985; Kendall, 2012). Surveys consisted of searching within the boundaries of the plot $\left(25 \mathrm{~m}^{2}\right)$ for $20 \mathrm{~min}$ and collecting individual leeches of both morphotypes (Figure 1). Searching was conducted mostly by either two or three researchers, but on nine occasions (due to logistics) the survey was conducted by a maximum of five people; we include this variation in sampling effort in our models as a survey-specific covariate. At sites where individuals were detected, we assigned the site as 1 , and where no individuals were detected within the time, we assigned the site as 0 . We did this for both species and each replicate survey, to generate detection histories for all sites.

\section{2 | Vegetation data}

To model the impact of forest structure on the occupancy probability of our leech species, we utilized vegetation data which was gathered from a LiDAR survey of the whole area conducted in 2014 (Jucker et al., 2018). For each vegetation plot, we extracted data for three vegetation structure covariates, using a 50-m buffer, which we determined a priori might have an influence on the probability of occupancy and detection of the leech species. These covariates were canopy height, habitat heterogeneity, and plant area index (PAI). Habitat heterogeneity ranges from -1 to 1 , representing a gradient from evenly dispersed canopies up to perfect clustering, while a value of zero represents perfectly random canopy dispersion. In practice, values approaching 1 indicate greater clustering of the canopy and thus represent strong contrasts in habitat availability such as gaps or very large trees within a matrix of intermediate canopy heights. Negative values are rare in natural forests, and intact, homogenous canopies would have values closer to zero. PAI is a measure of the density of leaves and branches in the canopy-their total one-sided area per unit area of ground. Before we used these
FIGURE 1 Focal leech species (a) brown leech, Haemadipsa sumatrana (photograph credit: R. Drinkwater) (b) tiger leech, Haemadipsa picta (photograph credit: S. J. Rossiter) taken in forest in Sabah, Borneo

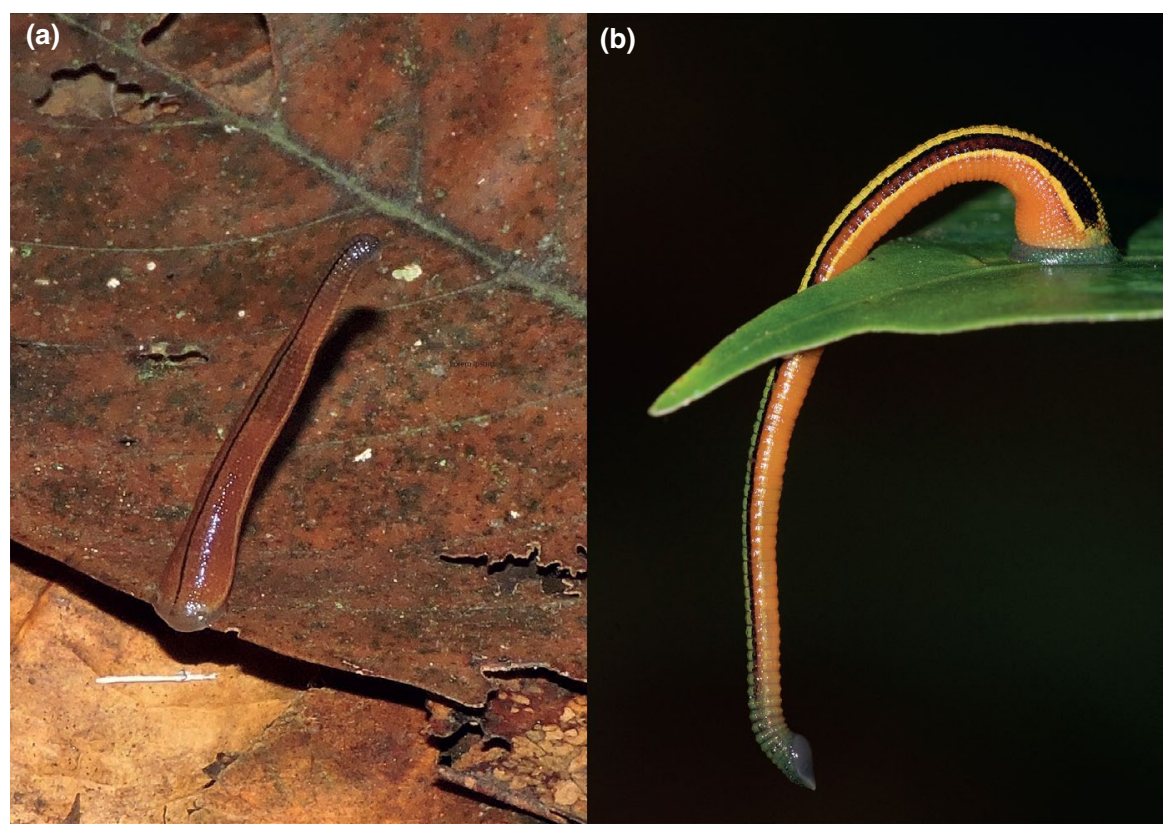


covariates in the models, we first tested for collinearity and found that canopy height and PAI have a strong and significant positive relationship. Thus, we removed PAI from the models and began by fitting models only using canopy height, as canopy height was found to be a buffer of microclimate extremes in the SAFE project landscape in a recent study (Jucker et al., 2018) (Figure S2). We used sampling effort (number of collectors per survey) and date of survey (Julian day per year) as survey-specific covariates.

\section{3 | Occupancy modeling}

For each of the leech species, we constructed single-season siteoccupancy models (MacKenzie et al., 2002) including the covariates described above. Firstly, to model the influence of habitat on leech occupancy, we incorporated the vegetation structure metrics (canopy height and habitat heterogeneity) as site-specific covariates which were modeled in relation to both occupancy and detection probability. Survey-specific covariates (survey day and sampling effort) relate to the observation process and reflect changes in detection probability between surveys. All covariates were scaled prior to inclusion in the model by centering on the mean value and standardizing by the standard deviation. The global model was as follows:

$z_{i} \sim \operatorname{Bernoulli}\left(\psi_{i}\right)$,logit $\left(\psi_{i}\right)=\beta_{0}+\beta_{1} *$ canopy height $_{i}+\beta_{2} *$ habitat clustering $_{i}$

$+\beta_{3} *$ canopy $_{\text {height }} *$ habitat clustering $_{i}$

$y_{i j} \mid z_{i} \sim \operatorname{Bernoulli}\left(z_{i} p_{i j}\right), \operatorname{logit}\left(p_{i j}\right)=\alpha_{0}+\alpha_{1} *$ canopy height $_{i}$

$+\alpha_{2}+$ habitat clustering $_{\mathrm{i}}+\alpha_{3} *$ date $_{i j}+\alpha_{4} *$ effort $_{i j}$,

where $z$ denotes the true occurrence state of species at site $i$ (i.e., presence $z=1$ or absence $z=0$ ). The parameter $\psi_{i}$ is the estimated proportion of occupied sites, while $p_{i j}$ is the probability of detecting the species at a site, during a survey, given its presence at the site. $\beta$ and $\alpha$ represent the site- and survey- specific covariates, which are incorporated into the model using a log-linear relationship to either occupancy $(\psi)$ or detection $(p)$ probability.

Assessment of goodness of fit was conducted in the same way for both sets of models; however, as the models on the reduced dataset (including mammals) did not show overdispersion, AIC was used for model selection and averaging, whereas quasi-AIC (QAIC) was used to evaluate the models on the full dataset (which did not include mammal abundance). We used the MacKenzie-Bailey goodness-of-fit test, bootstrapped over 5,000 iterations, on the global model, to assess the lack of model fit. From this global model, we generated models with different combinations of covariates and evaluated them using QAIC (or AIC). In all four scenarios (the brown and tiger leech in both the dry and wet seasons), there was no single best model where $\triangle \mathrm{QAIC}$ (or $\triangle \mathrm{AIC}$ ) was greater than two to the next best model. To account for this uncertainty, we used a model averaging approach (Burnham \& Anderson, 2002) using models with a cumulative weight $\leq 0.95$ and a $\triangle \mathrm{QAIC}$ (or $\triangle \mathrm{AIC}$ ) of less than two to calculate the full model average of the coefficients (Symonds \&
Moussalli, 2011). All models were constructed and analyzed using maximum likelihood methods in the unmarked package (Fiske \& Chandler, 2011), and model averaging was conducted using the MuMIn package (Bartoń, 2018) in R (R Core Team 2018).

\section{4 | Mammal abundance}

To test whether abundance of available prey influences leech detectability, we used a reduced leech survey dataset to compare the fit of models with and without the inclusion of mammal abundance as a covariate. In this study, we focus on mammals as a measure of available prey, because previous studies conducted in the same area were unsuccessful in detecting any other vertebrate groups in the diets of these two Bornean leech species (Drinkwater et al., 2018; Schnell et al., 2018). Firstly, we generated the covariate for mammal abundance from camera traps which had been deployed across the SAFE landscape from 2015 to 2017. To identify the leech survey locations which overlapped with cameras, first we pooled all camera traps within $320 \mathrm{~m}$ of one another and recalculated a centroid point from their GPS locations. Total mammal abundance was calculated from the pooled camera detections and divided by pooled camera trap night to account for differential sampling effort. Next, from the new centroid coordinate, we identified leech survey sites within $320 \mathrm{~m}$ and used these data as spatial replication for the detection histories. This resulted in a reduced number of leech surveys, which could be used in this analysis. LiDAR metrics (canopy height and habitat heterogeneity) were also pooled from their associated leech survey points. Models were constructed which had the optimal structure without the inclusion of mammals (identified from initial analysis of the full dataset) and with the addition of mammal abundance. AIC values were compared to evaluate whether the inclusion of mammals increases the model fit.

\subsection{Thermal tolerance}

Between May and October 2018, brown and tiger leeches were collected along a 500-m transect in the logged forest edge plot at the SAFE project. Leeches were placed individually into $25-\mathrm{ml}$ polyethylene falcon tubes and kept in a cool, shaded location before thermal tolerance assays were performed. We investigated the maximum thermal tolerances for both leech species using the standard protocol dictated by (Chown, Jumbam, Sørensen \& Terblanche, 2009). Individuals were placed in $25-\mathrm{ml}$ polyethylene falcon tubes submerged in a water bath. Temperature was raised to $34^{\circ} \mathrm{C}$ for 5 minutes and subsequently increased by $0.1^{\circ} \mathrm{C}$ per minute up to a maximum of $43^{\circ} \mathrm{C}$, slow enough to decrease the chances of a delayed response to temperature increase, but fast enough to limit the chances of death through factors such as desiccation. The critical thermal maximum ( $\mathrm{CT}_{\mathrm{MAX}}$ ) is the temperature at which muscles begin to spasm and behavior is uncontrolled (Lutterschmidt \& Hutchinson, 1997). In these assays, the $\mathrm{CT}_{\text {MAX }}$ was taken when individuals were 
unable to "walk" along the tubes; instead, they hung limply and spasmed, or were no longer upright and were contracting and relaxing along the anterior-posterior axis. Body length and species were then recorded for each individual.

\section{3 | RESULTS}

\subsection{Occupancy and detection probability}

Before accounting for the effects of site- and survey-specific differences, there were no significant differences between the probability of occupancy and detection probability between species in either season (Figure 2, Table S1). In the dry season, the occupancy probability at a site without accounting for habitat variability was $0.89( \pm 0.03 \mathrm{SE})$ for the brown leech and $0.83( \pm 0.03 \mathrm{SE})$ for the tiger leech. During the wet season, occupancy was $0.82( \pm 0.05$ $S E)$ for the brown leech and $0.86( \pm 0.05 S E)$ for the tiger leech. Detection probabilities were also similar for both species in both seasons: $0.56( \pm 0.02 \mathrm{SE})$ and $0.63( \pm 0.02 \mathrm{SE})$ for the brown and tiger leech, respectively, in the dry season, and 0.59 ( $\pm 0.03 \mathrm{SE}$ ) and $0.54( \pm 0.03 \mathrm{SE})$ for the brown and tiger leech, respectively, in the wet season.
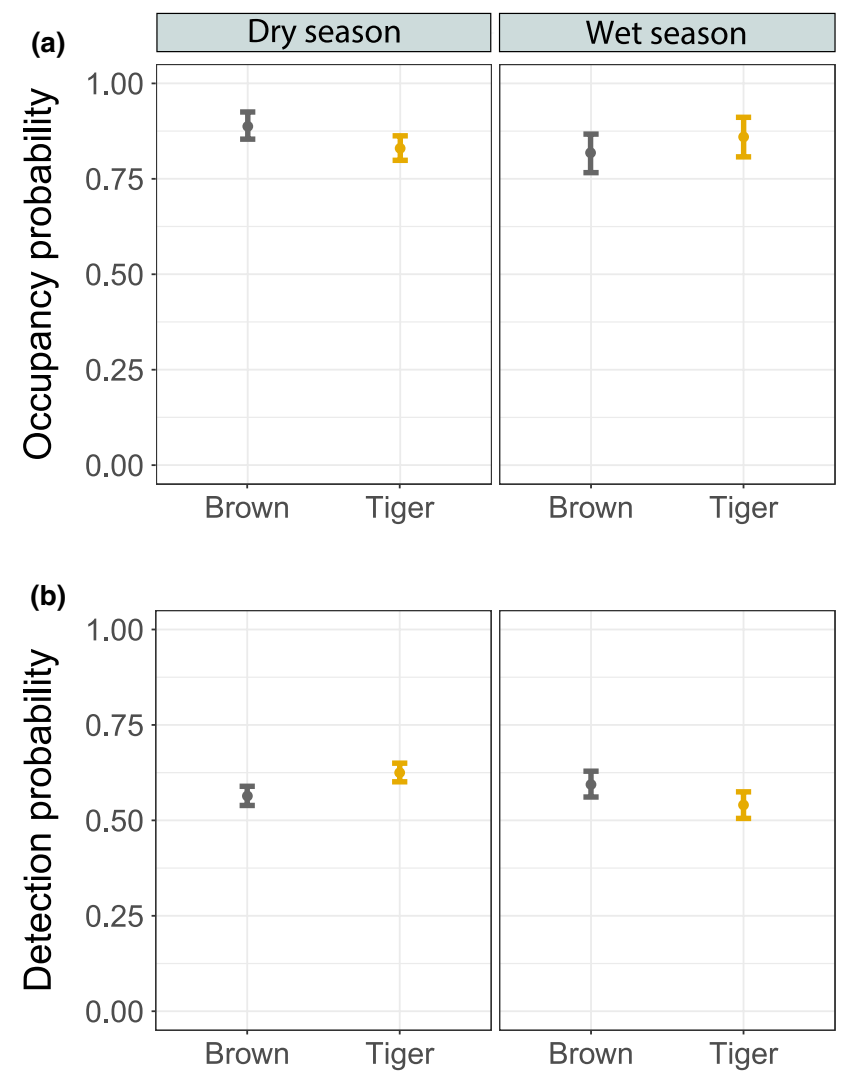

FIGURE 2 (a) Occupancy probability and (b) detection probability for both leech species, shown for both surveys in the wet and dry seasons, including standard errors. Estimate for models which include no site or survey covariates

\subsection{Impact of site and sampling differences on species detection probability}

Detection probabilities are positively influenced by canopy height (Figure 3a,d,g,j, full model-averaged coefficients: brown$\mathrm{DRY}=0.63 \pm 0.11 \mathrm{SE}$, tiger $_{\mathrm{DRY}}=0.80 \pm 0.12 \mathrm{SE}$, brown $_{\mathrm{WET}}=0.46 \pm 0.14$ $S E$, tiger $_{\text {WET }}=0.47 \pm 0.14 S E$ ). Only the tiger leech surveyed during the wet season showed a negative relationship with habitat heterogeneity, increasing heterogeneity reduced detection probability (Figure $4 \mathrm{k}$, tiger ${ }_{\mathrm{WET}}=-0.23 \pm 0.12 \mathrm{SE}$ ). Sampling effort showed various responses; during the dry survey season, the detection probability of the brown leech has a positive relationship with sampling effort (Figure 4c, $0.23 \pm 0.13 \mathrm{SE}$ ). In the wet season, counterintuitively, detection probability has a negative relationship with increasing effort (Figure 4i,l, brown $_{\mathrm{WET}}=-0.36 \pm 0.36 \mathrm{SE}$, tiger $_{\mathrm{WET}}=-0.85 \pm 0.34 \mathrm{SE}$ ). Sampling effort has no effect on the detectability of the tiger leech during the dry season and was not retained in the optimal model.

\section{3 | Impact of habitat variability on site occupancy}

Across seasons and for both species, the top-ranked models, i.e., those within a $\triangle$ QAIC of 2 of the model with the lowest QAIC, show a high degree of consistency in model structure (Table 1). These models were averaged, accounting for uncertainty in model choice, and the average coefficient estimates (Table 2) were used to predict the siteoccupancy probability across a range of the site-specific covariates of canopy height and habitat heterogeneity. Canopy height was retained as a covariate in the optimal model for all four scenarios, yet the probability of site occupancy only shows a small relationship with increasing canopy height in the wet survey seasons and for the tiger leech in the dry season (Figure 4c,e,g, full model-averaged coefficients: brown-

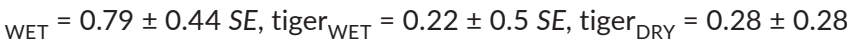
$S E)$. However, there is no effect of canopy height on brown leech occupancy in the dry season (Figure $4 a$, brown $n_{D R Y}=0.04 \pm 0.21 \mathrm{SE}$ ). Habitat heterogeneity has little effect on occupancy, expect for on the brown leech during the dry season, where heterogeneous habitats have lower occupancy (Figure $4 b$, brown $n_{D R Y}=-0.81 \pm 0.43 \mathrm{SE}$ ).

\subsection{Effect of mammalian prey abundance}

For each scenario, we used the optimal model structure from the model selection above, as the basis for the addition of the mammal abundance covariate and assessment of model fit (Table 1). The initial structures used were as follows:

$$
\begin{gathered}
\text { brown } \left._{\mathrm{DRY}}=\psi(.) p \text { (effort }+ \text { height }\right) \\
\text { tiger } \left._{\mathrm{DRY}}=\psi(\text { height }) p \text { (date }+ \text { height }\right) \\
\text { brown } \left._{\mathrm{WET}}=\psi(.) p \text { (effort }+ \text { height }\right) \\
\text { tiger }_{\mathrm{WET}}=\psi(.) p(\text { effort }+ \text { height })
\end{gathered}
$$

We find that for the brown leech in both the dry and wet seasons, the inclusion of mammal abundance increases the model fit for the 


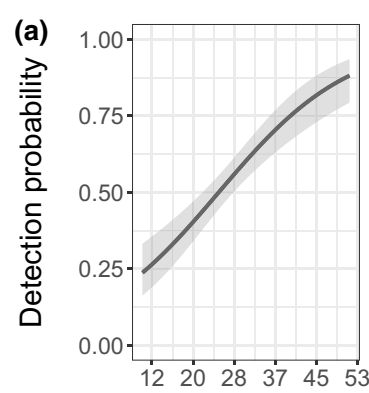

(b)

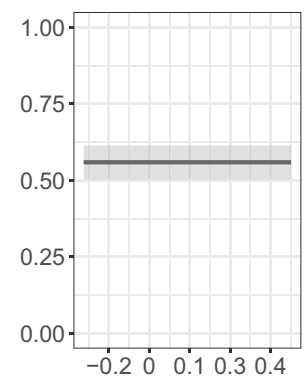

(c)
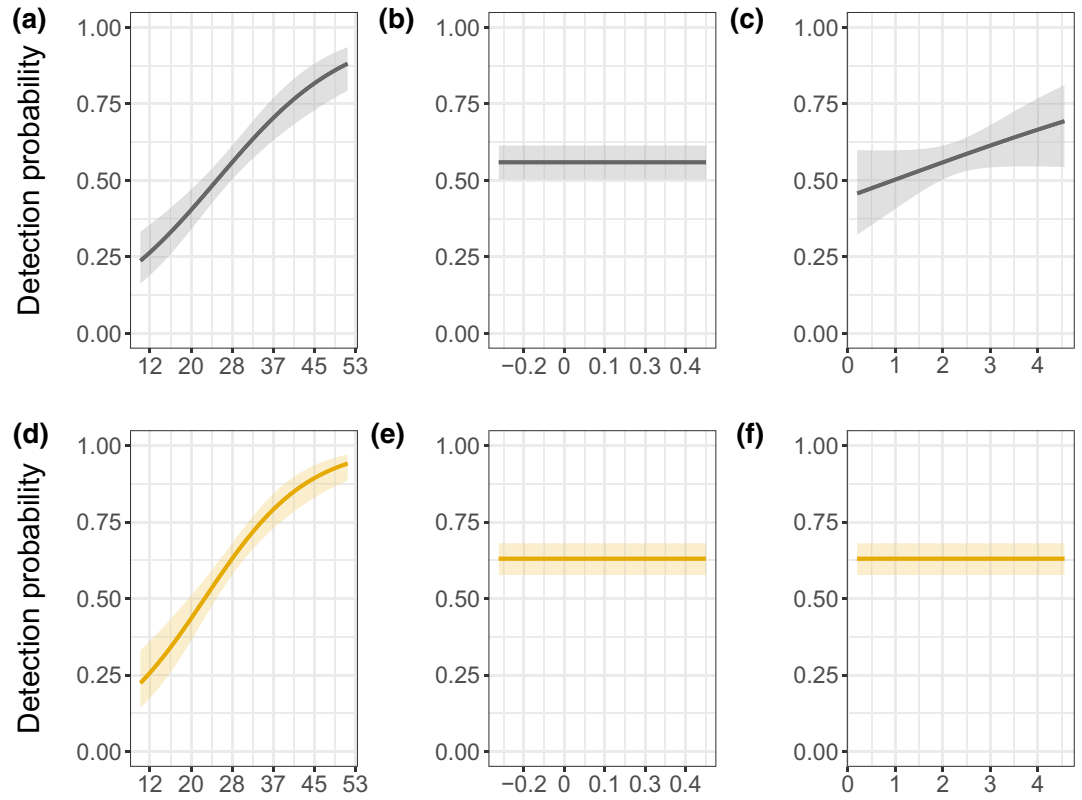

(e)

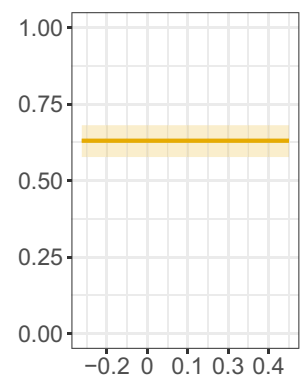

(f)
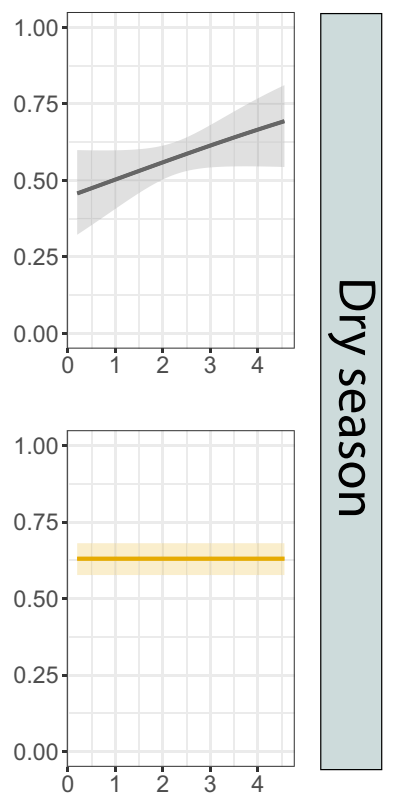

(h)

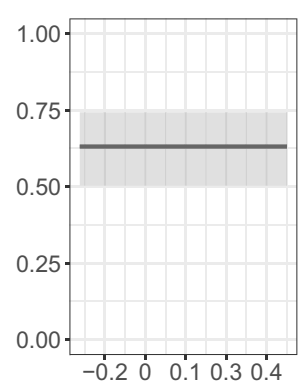

(i)

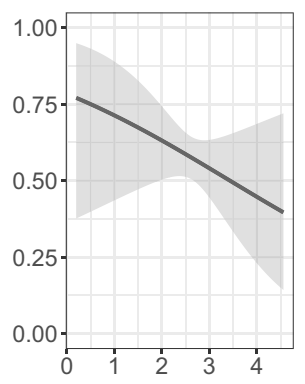

(I)

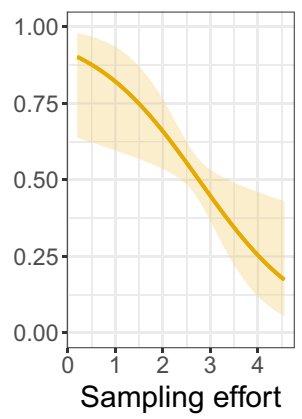

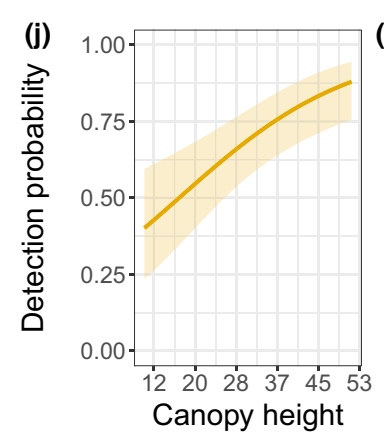

(k)

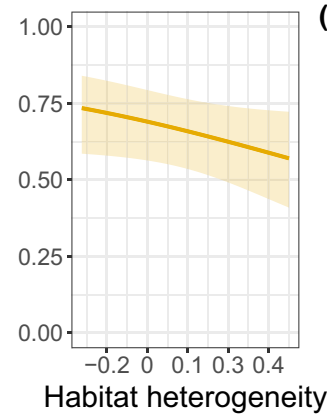

FIGURE 3 Leech detection probability with site- and survey-specific covariates. Brown leech responses are shown in gray (a-c \& g-i), and tiger leech responses are shown in yellow $(d-f \& j-l)$. The top half shows changes in detection probability in the dry season, depending on canopy height $(a, d)$, habitat heterogeneity $(b, e)$, and sampling effort (c, f). The bottom half shows changes to the same covariates (canopy height $=\mathrm{g} \& \mathrm{j}$, heterogeneity $=\mathrm{h}$ $\& k$, and sampling effort ( $i$ l) for surveys conducted during the wet season. Sampling effort is measured as the number of collectors searching for individuals during each survey; canopy height is in meters, and heterogeneity is measured using Moran's I reduced dataset as shown by a reduction in the AIC value between the original model and those models which include mammal abundance (Table 3, brown $n_{\text {DRY }} \Delta \mathrm{AIC}=2.52$, brown WET $\Delta \mathrm{AIC}=3.18$ ). . The impact of including mammal abundance on tiger leech detection is less clear. In both seasons, for the tiger leech, the inclusion of mammal abundance shows some improvements in model fit; however, these are small (within $\triangle \mathrm{AIC}<2$ ). In all cases, however, the original model structure (without including mammals) for all four scenarios has strong support, and thus, no clear conclusions can be drawn about the influence of mammals driving leech detection probability.

\subsection{Thermal tolerance}

Physiological thermal tolerance $\left(\mathrm{CT}_{\mathrm{MAX}}\right)$ did not differ between the brown and tiger leeches $\left(40.3 \pm 0.29^{\circ} \mathrm{C} S E\right.$ vs. $40.2 \pm 0.32^{\circ} \mathrm{C} \mathrm{SE}$,
Mann-Whitney $U$ test, $W=178.5, p=0.75$, Figure 5). $\mathrm{CT}_{\text {MAX }}$ was predicted by a second-degree polynomial of $\log _{10}$ leech length (polynomial regression, $p<0.01, d f=36$ ).

\section{DISCUSSION}

Terrestrial leeches are an abundant yet poorly studied invertebrate group in tropical ecosystems. We compared the factors affecting leech occurrence in a degraded landscape in Sabah, Borneo. Our findings revealed that across wet and dry seasons, the brown and tiger leeches are both more easily detected in forest with a higher canopy. This is probably due to a more humid microclimate that allows leeches to be active and thus more visible during daytime surveys. Indeed, a recent study from Borneo indicated that 
FIGURE 4 Changes in leech occupancy probability over a habitat gradient in the dry season (top half) and the wet season (bottom half). Brown leech responses are shown in gray (a, b, e \& f), and tiger leech responses are shown in yellow (c, $d, g \& h)$. The effects of canopy height and habitat heterogeneity are shown for both seasons. Canopy height is measured in meters, and habitat heterogeneity is measured using Moran's I

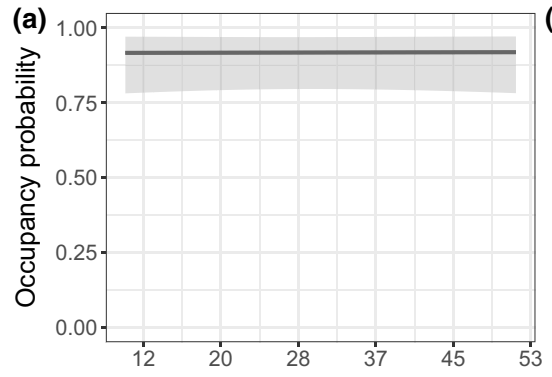

(b)
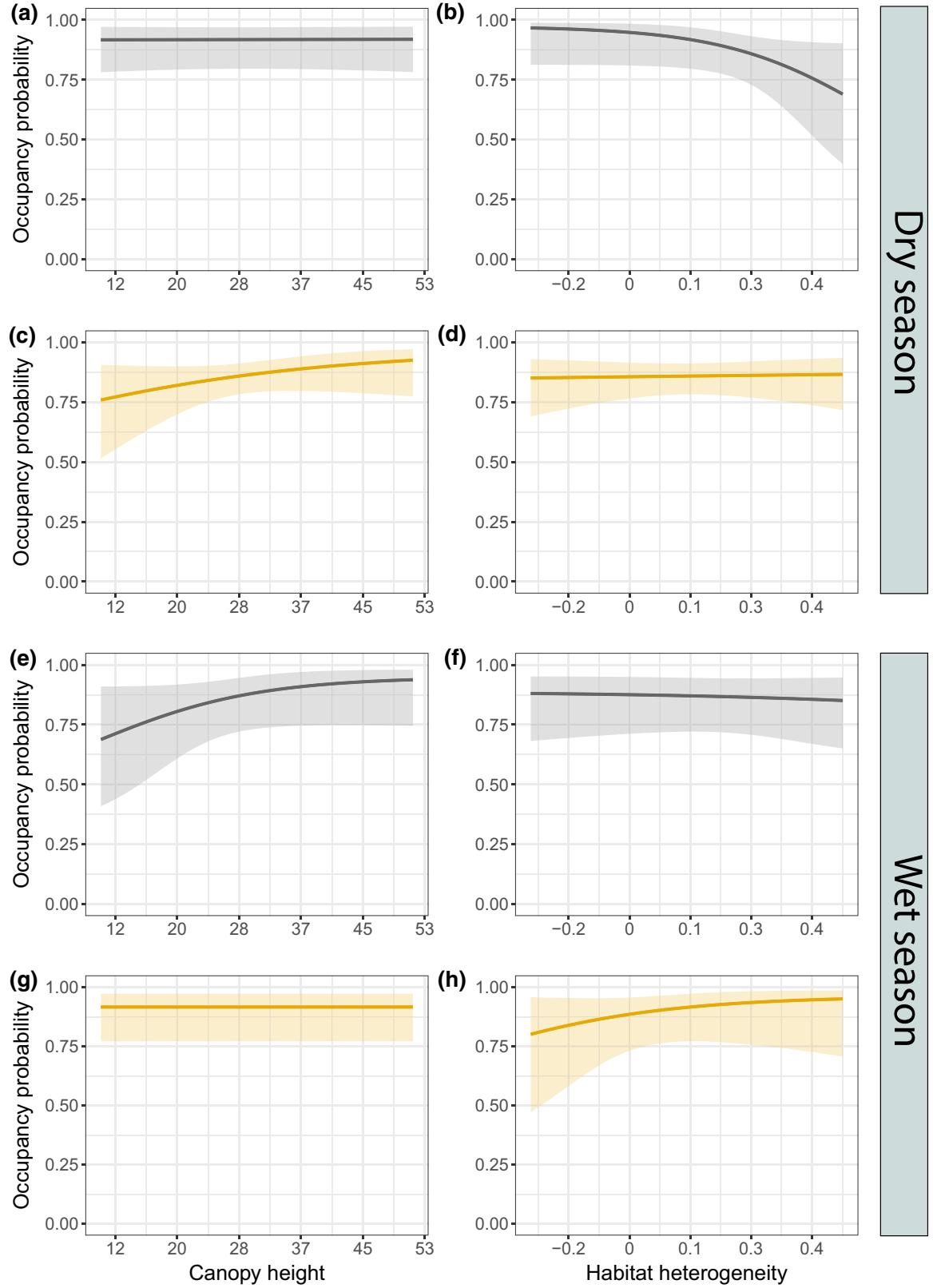

canopy height has a dampening effect on microclimatic extremes in both temperature and humidity (Jucker et al., 2018). In contrast, we found no clear effect of habitat heterogeneity on leech detectability. In terms of occupancy, similar broad trends were observed for the tiger leech, with a positive effect of canopy height on presence regardless of season. However, for the brown leech this association was only seen in the wet season, with no apparent effect of canopy height during the dry season. Habitat heterogeneity showed the opposite trend to occupancy; the brown leech was less likely to occur in heterogeneous habitats during the extended dry season of the El Niño year. Given that this heterogeneity is characteristic of heavily degraded forest, our results may imply that brown leech presence is influenced by an interaction between habitat quality and microclimate. Previous studies have shown that heavily fragmented tropical forests are particularly vulnerable to the effects of wind disturbance and increased solar radiation, which lead to soil desiccation and elevated evapotranspiration (Laurance, 2004). If terrestrial leeches are susceptible to drier soil conditions, we may thus expect leeches to respond negatively to forest degradation and fragmentation, symptoms of which are likely to include elevated habitat heterogeneity and decreased canopy height.

Although there has been little work to date on terrestrial leech habitat preferences, Tan et al. (1989) studied Haemadipsa hainana in rubber (Hevea brasiliensis) plantations on Hainan, a tropical offshore island in Southeast China. By investigating the influence of abiotic conditions and vegetation on leech abundance, the authors demonstrated a positive correlation with precipitation and also showed a positive but nonsignificant association with canopy cover. Followon work showed that leeches were less abundant in the dry season and that rainfall was the most important explanatory variable (Tan \& Liang, 2000). However, given that these studies were conducted in 
TABLE 1 Candidate set of models, selected for model averaging which had a $\triangle$ QAIC value of two. This is the model set with approximately $95 \%$ confidence levels. $\psi$ denotes occupancy probability, and $p$ denotes detection probability

\begin{tabular}{|c|c|c|c|}
\hline Model structure & QAIC & $\triangle Q A I C$ & Weight \\
\hline \multicolumn{4}{|l|}{ Brown leeches-Dry } \\
\hline$\psi() p.($ effort + height $)$ & 245.75 & 0.00 & 0.47 \\
\hline$\psi($ moran $) p($ effort + height $)$ & 246.31 & 0.56 & 0.36 \\
\hline$\psi$ (height) $p$ (effort + height $)$ & 247.74 & 1.99 & 0.17 \\
\hline \multicolumn{4}{|l|}{ Tiger leeches-Dry } \\
\hline$\psi$ (height) $p$ (date + height $)$ & 342.88 & 0.00 & 0.49 \\
\hline$\psi($ moran $) p($ date + height $)$ & 343.73 & 0.85 & 0.32 \\
\hline $\begin{array}{c}\psi(\text { height }+ \text { moran }) \\
p(\text { date }+ \text { height })\end{array}$ & 344.88 & 1.99 & 0.18 \\
\hline \multicolumn{4}{|l|}{ Brown leeches-Wet } \\
\hline$\psi()$.$p (effort + height)$ & 174.24 & 0.00 & 0.48 \\
\hline$\psi($ height $) p$ (effort + height) & 175.08 & 0.84 & 0.32 \\
\hline$\psi($ moran $) p$ (effort + height $)$ & 176.04 & 1.80 & 0.20 \\
\hline \multicolumn{4}{|l|}{ Tiger leeches-Wet } \\
\hline$\psi()$.$p (effort + height)$ & 219.16 & 0.00 & 0.72 \\
\hline $\begin{array}{l}\psi(\text { moran }) \\
p(\text { effort }+ \text { height }+ \text { moran })\end{array}$ & 221.08 & 1.92 & 0.28 \\
\hline
\end{tabular}

TABLE 2 The coefficient estimates from the model average for each leech species and season with the associated standard errors

\begin{tabular}{|c|c|c|c|}
\hline \multicolumn{2}{|l|}{ Dry surveys } & \multirow{2}{*}{$\frac{\text { Brown }}{\text { Estimate }}$} & \multirow{2}{*}{$\frac{\text { Tiger }}{\text { Estimate }}$} \\
\hline Occupancy & Covariate & & \\
\hline & Intercept & $2.48(0.57)$ & $1.81(0.27)$ \\
\hline & Height & $0.037(0.21)$ & $0.28(0.28)$ \\
\hline & Heterogeneity & $-0.81(0.43)$ & $0.02(0.17)$ \\
\hline & $\begin{array}{l}\text { Height/ } \\
\text { Heterogeneity }\end{array}$ & $-0.008(0.12)$ & - \\
\hline \multirow[t]{5}{*}{ Detection } & Intercept & $0.23(0.11)$ & $0.53(0.11)$ \\
\hline & Height & $0.63(0.11)$ & $0.80(0.12)$ \\
\hline & Moran & - & - \\
\hline & Effort & $0.23(0.13)$ & - \\
\hline & Date & - & $-0.38(0.10)$ \\
\hline \multicolumn{2}{|l|}{ Wet surveys } & Brown & Tiger \\
\hline \multirow[t]{5}{*}{ Occupancy } & Covariate & Estimate & Estimate \\
\hline & Intercept & $1.83(0.46)$ & $2.33(0.61)$ \\
\hline & Height & $0.79(0.44)$ & $0.22(0.50)$ \\
\hline & Heterogeneity & $-0.15(0.31)$ & $0.42(0.48)$ \\
\hline & $\begin{array}{l}\text { Height/ } \\
\text { Heterogeneity }\end{array}$ & $0.03(0.18)$ & $0.14(0.40)$ \\
\hline \multirow[t]{5}{*}{ Detection } & Intercept & $0.54(0.27)$ & $0.66(0.26)$ \\
\hline & Height & $0.46(0.14)$ & $0.47(0.14)$ \\
\hline & Heterogeneity & - & $-0.23(0.12)$ \\
\hline & Effort & $-0.32(0.36)$ & $-0.85(0.34)$ \\
\hline & Date & - & - \\
\hline
\end{tabular}

TABLE 3 Model selection using AIC for the effects of including mammal abundance per camera trap night as a detection covariate. Models are tested using a reduced dataset which is spatially matched to camera trap data

\begin{tabular}{|c|c|c|c|}
\hline Model structure & AIC & $\Delta \mathrm{AIC}$ & AlCweight \\
\hline \multicolumn{4}{|l|}{ Brown leeches-Dry } \\
\hline Mammal + effort & 308.63 & 0.00 & 0.33 \\
\hline Mammal only & 309.20 & 0.57 & 0.25 \\
\hline Mammal + original & 310.36 & 1.72 & 0.14 \\
\hline Mammal + habitat & 311.04 & 2.41 & 0.1 \\
\hline Null & 311.11 & 2.48 & 0.1 \\
\hline Original & 311.15 & 2.52 & 0.09 \\
\hline \multicolumn{4}{|l|}{ Brown leeches-Wet } \\
\hline Mammal only & 206.49 & 0.00 & 0.34 \\
\hline Mammal + habitat & 207.54 & 1.05 & 0.20 \\
\hline Null & 207.94 & 1.45 & 0.16 \\
\hline Mammal + effort & 208.14 & 1.65 & 0.15 \\
\hline Mammal + original & 209.23 & 2.75 & 0.09 \\
\hline Original & 209.67 & 3.18 & 0.07 \\
\hline \multicolumn{4}{|l|}{ Tiger leeches-Dry } \\
\hline Mammal + habitat & 272.37 & 0.00 & 0.46 \\
\hline Original & 273.04 & 0.67 & 0.33 \\
\hline Mammal + original & 273.97 & 1.60 & 0.21 \\
\hline Mammal + date & 294.14 & 21.78 & $<0.001$ \\
\hline Mammal only & 294.34 & 21.97 & $<0.001$ \\
\hline Null & 295.02 & 22.66 & $<0.001$ \\
\hline \multicolumn{4}{|l|}{ Tiger leeches-Wet } \\
\hline Mammal + habitat & 214.80 & 0.00 & 0.30 \\
\hline Null & 215.12 & 0.31 & 0.25 \\
\hline Original & 215.44 & 0.64 & 0.21 \\
\hline Mammal + original & 216.80 & 2.00 & 0.11 \\
\hline Mammal only & 216.95 & 2.15 & 0.10 \\
\hline Mammal + effort & 218.93 & 4.13 & 0.04 \\
\hline
\end{tabular}

plantations, which are typically characterized by low levels of understory and few vertebrates, they provide few insights into natural forest dynamics. Using an experimental approach, Tan (2001) exposed leeches to a gradient of soil moisture in the laboratory and found that individuals were unable to survive on soil with $<15 \%$ water content, which is expected to be higher than the water content of soils exposed to sunlight. In an unpublished study of the brown and tiger leech at our focal site, Kendall (2012) showed that the encounter rate of brown leeches decreased in logged forest. More recently, Fahmy et al. (2019) also found differences in the abundance of Madagascan terrestrial leeches (Chtonobdella spp.) across sites with different levels of forest disturbance, indicating that these species could be potential indicators of forest quality.

Interestingly, the inferred sensitivity of leeches to drier conditions was also supported indirectly by the results of our assays of physiological thermal tolerance, which showed no difference 


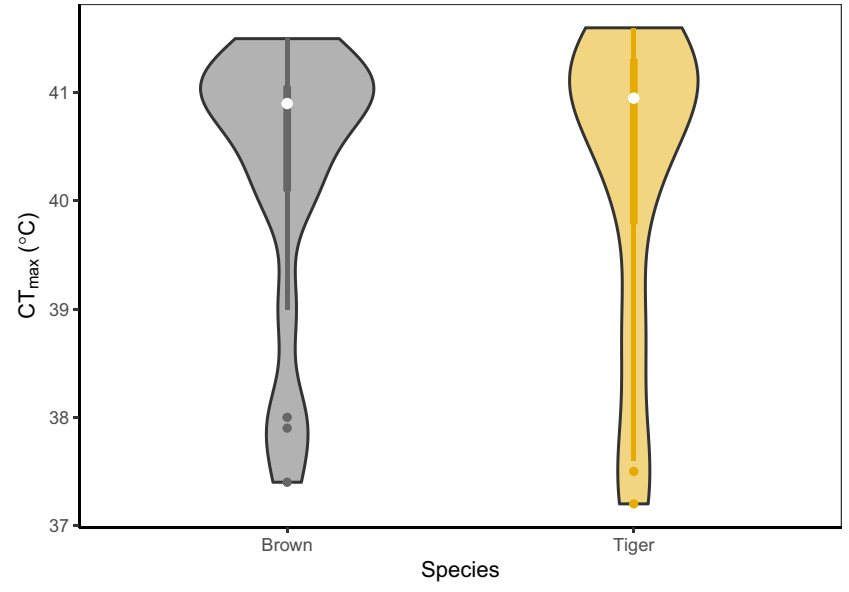

FIGURE 5 Violin plot showing the variation in critical thermal maxima $\left(C T_{M A X}\right)$ between the brown and tiger leeches

between the brown and tiger leeches to temperature per se. $\mathrm{CT}_{\mathrm{MAX}}$ were highly left-skewed with many low values given the medians, potentially demonstrating the difficulties with using these methods on leeches. Leech behavior was difficult to quantify, and thus, accurate readings of $\mathrm{CT}_{\mathrm{MAX}}$ were hard to ascertain. We suggest that the cause of our non-normal error distributions was the early desiccation of leeches with smaller surface area: volume ratios during the assay. This would explain the apparent relationship between leech length and $\mathrm{CT}_{\mathrm{MAX}}$. Therefore, it is probable that desiccation tolerance, rather than thermal tolerance, is a more important determinant of leech occurrence, and certainly this is consistent with the restricted distribution of terrestrial leech species to humid biomes, rather than to hot ones (Mann, 1962). The sensitivity of soft-bodied invertebrates to desiccation rather than high temperatures has also been shown for termites from work in degraded Malaysian forests (Woon, Boyle, Ewers, Chung \& Eggleton, 2019). For terrestrial leeches, additional experimental work is thus needed to test the explicit effects of humidity.

Aside from examining their potential value as ecological indicators, we set out to examine whether leeches could be used to noninvasively estimate mammal abundance or diversity (also see Fahmy et al., 2019); such a finding would indicate that leeches could complement other sampling methods such as camera traps. Our models of leech detection probability that included mammal abundance as a covariate fitted the data better than those without mammals, indicating a relationship between detectability of leeches and mammalian prey presence. However, the overall effect size was small, and the improved fit was only apparent for the brown leech detection models. Additionally, our results were based on a substantially reduced subset of leech surveys as a consequence of the paucity of spatially matched sampling sites for leeches and mammals. Therefore, to demonstrate more comprehensively the potential link between terrestrial leech presence and mammalian abundance, both spatially and temporally, cohesive sampling designs would be needed. Indeed, as ecological processes tend to be scale dependent, the importance of defining spatial extent and resolution of covariates can influence occupancy probability (Niedballa, Sollmann, Mohamed, Bender \& Wilting, 2015). Furthermore, different biodiversity metrics could be used instead of mammal abundance, such as biomass or evenness, which might be more realistic and/or important for leeches. As previous molecular work has demonstrated, both of our focal species of leech tend to feed preferentially on larger-bodied mammals, with very little DNA from small mammals detected in their blood meals (Drinkwater et al., 2018). Therefore, a more nuanced metric of mammalian biodiversity, that considers leech feeding behavior, may yet reveal stronger associations.

Although our study suggests occupancy models are useful for understanding the habitat requirements of leeches, these approaches require that a set of assumptions are met (MacKenzie et al., 2006). Meeting the assumption of site closure, i.e., sites are closed to changes in occupancy over a sampling period, is important in ensuring unbiased estimates of occupancy. The independent mobility of ectoparasitic invertebrates, including terrestrial leeches, or the extent to which their movement is mediated by their hosts, is a factor that has the potential to violate the closure assumption. While we attempted to compensate for this by conducting our replicate samples over a short time-frame, the dispersal ability of terrestrial leeches is still poorly understood. Nevertheless, the foraging strategy of leeches, in which individuals "sit-and-wait" for passing prey, would imply that active dispersal is limited. Additionally, differences in species' behaviors may also affect the assumption of constant detection probability across sites (MacKenzie et al., 2006); for example, the brown leech tends to forage on the forest floor and is camouflaged in the leaf litter, whereas the brighter-colored tiger leech is more conspicuous and tends to forage from vegetation in the understory. Additionally, our results suggest that there is a negative relationship between sampling effort and detection probability, but only in the wet season. Potentially this observation is due to overharvesting, where populations of leeches are declining as sampling effort increases. This is a concern that has been raised in molecular blood-meal studies for biodiversity monitoring, especially concerning terrestrial leeches (Schnell et al., 2015).

It is over 30 years since Fogden and Proctor (1985), in a paper published in Biotropica, suggested that haemadipsid leeches are at risk of declines with increased logging. We show that leech occurrence is influenced by differences in vegetation structure associated with forest degradation. Yet despite Fogden \& Proctor's warning, and the burgeoning interest in terrestrial leeches for biomonitoring, surprisingly little is known about their ecological roles and the consequences of their loss from ecosystems. Certainly, our findings suggest that, in the face of large-scale habitat degradation in the tropics, logged forests with some degree of canopy will be important for the persistence of terrestrial leeches and other invertebrates. As such, our findings add to the growing body of work that supports the conservation value of selectively logged forest in human-modified tropical landscapes (Deere et al., 2017; Edwards et al., 2011; Senior, Hill, Benedick \& Edwards, 2018). 


\section{ACKNOWLEDGMENTS}

We would like to thank two anonymous reviewers for constructive feedback on the manuscript. We thank Henry Bernard (Universiti Malaysia Sabah) for his support in Malaysia. We also thank Yayasan Sabah, Benta Wawasan, and Sime Darby for granting access to field sites. We are grateful to Esther Baking and the many research assistants and students at the Stability of Altered Forest Ecosystems (SAFE) project for support with fieldwork. We thank Omar Khalilur Rahman, Vinnie Siow, and Haris Ridwan for the abstract translation to Bahasa Malaysia. RD and SJR supported a Natural Environment Research Council grant NE/K016148/1, awarded as part of the Human Modified Tropical Forests Programme, and RD received additional support from a Study Abroad Studentship (SAS-2016-100) awarded by The Leverhulme Trust.

\section{DATA AVAILABILITY}

The data used in this study are archived on the Zenodo data repository within the SAFE project community pages, https://doi. org/10.5281/zenodo.2536269, and the scripts used to generate figures and statistics are available https://github.com/rosiedrink/ leech-occurrence.

\section{ETHICAL APPROVAL}

In this study, all experimental procedures involving the use of animals were made in accordance with the ethical standards of the institute where this took place. Fieldwork was conducted under the approval of the Sabah Biodiversity Council (for RD - JKM/MBS.1000-2/2 (374), JKM/MBS.1000-2/3 JLD.2 (55), for JW - JKM/MBS.1000-2/2 JLD.7 (83)).

\section{ORCID}

Rosie Drinkwater (iD https://orcid.org/0000-0001-6892-1664

Joseph Williamson iD https://orcid.org/0000-0003-4916-5386

Tom Swinfield iD https://orcid.org/0000-0001-9354-5090

Nicolas J. Deere (iD http://orcid.org/0000-0003-1299-2126

Matthew J. Struebig iD https://orcid.org/0000-0003-2058-8502

Elizabeth L. Clare (iD https://orcid.org/0000-0002-6563-3365

Stephen J. Rossiter (iD https://orcid.org/0000-0002-3881-4515

\section{REFERENCES}

Andresen, E., \& Laurance, S. (2006). Possible indirect effects of mammal hunting on dung beetle assemblages in Panama. Biotropica, 39, 141-146. https://doi.org/10.1111/j.1744-7429.2006.00239.x

Bailey, L. L., Mackenzie, D. I., \& Nichols, J. D. (2014). Advances and applications of occupancy models. Methods in Ecology and Evolution, 5, 1269-1279. https://doi.org/10.1111/2041-210X.12100

Bartoń, K. (2018). MuMIn: Multi-Model Inference. R package version 1.43.6. Retrieved from https://CRAN.R-project.org/package=MuMIn
Borda, E., Oceguera-Figueroa, A., \& Siddall, M. E. (2008). On the classification, evolution and biogeography of terrestrial haemadipsoid leeches (Hirudinida: Arhynchobdellida: Hirudiniformes). Molecular Phylogenetics and Evolution, 46, 142-154. https://doi.org/10.1016/j. ympev.2007.09.006

Borda, E., \& Siddall, M. E. (2010). Insights into the evolutionary history of Indo-Pacific bloodfeeding terrestrial leeches (Hirudinida: Arhynchobdellida: Haemadipisdae). Invertebrate Systematics, 24, 456-472. https://doi.org/10.1071/IS10013

Burnham, K. P., \& Anderson, D. R. (2002). A practical information-theoretic approach. Model selection and multimodel inference (2nd Edn). New York, NY: Springer.

Calvignac-Spencer, S., Leendertz, F. H., Gilbert, M. T. P., \& Schubert, G. (2013). An invertebrate stomach's view on vertebrate ecology. BioEssays, 35, 1004-1013. https://doi.org/10.1002/bies.20130 0060

Calvignac-Spencer, S., Merkel, K., Kutzner, N., Kühl, H., Boesch, C., Kappeler, P. M., ... Leendertz, F. H. (2013). Carrion fly-derived DNA as a tool for comprehensive and cost-effective assessment of mammalian biodiversity. Molecular Ecology, 22, 915 - 924. https://doi. org/10.1111/mec.12183

Chown, S. L., Jumbam, K. R., Sørensen, J. G., \& Terblanche, J. S. (2009). Phenotypic variance, plasticity and heritability estimates of critical thermal limits depend on methodological context. Functional Ecology, 23, 133-140. https://doi.org/10.1111/j.1365-2435.2008.01481.x

Cortelezzi, A., Gullo, B. S., Simoy, M. V., Cepeda, R. E., Marinelli, C. B., Rodrigues Capítulo, A., \& Berkunsky, I. (2018). Assessing the sensitivity of leeches as indicators of water quality. Science of the Total Environment, 624, 1244-1249. https://doi.org/10.1016/j.scito tenv.2017.12.236

de Campos Brites, V. L., \& Rantin, F. T. (2004). The influence of agricultural and urban contamination on leech infestation of freshwater of the Uberabinha river. Environmental Monitoring and Assessment, 96, 273-281. https://doi.org/10.1023/B:EMAS.00000 31733.98410.3c

Deere, N. J., Guillera-Arroita, G., Baking, E. L., Bernard, H., Pfeifer, M., Reynolds, G., ... Struebig, M. J. (2017). High Carbon Stock forests provide co-benefits for tropical biodiversity. Journal of Applied Ecology, 55, 1-12. https://doi.org/10.1111/1365-2664.13023

Drinkwater, R., Schnell, I. B., Bohmann, K., Bernard, H., Veron, G., Clare, E., ... Rossiter, S. J. (2018). Using metabarcoding to compare the suitability of two blood-feeding leech species for sampling mammalian diversity in North Borneo. Molecular Ecology Resources, 19, 1-13. https://doi.org/10.1111/1755-0998.12943

Edwards, D. P., Larsen, T. H., Docherty, T. D. S., Ansell, F. A., Hsu, W. W., Derhé, M. A., ... Wilcove, D. S. (2011). Degraded lands worth protecting: The biological importance of Southeast Asia's repeatedly logged forests. Proceedings of the Royal Society B: Biological Sciences, 278, 82-90. https://doi.org/10.1098/rspb.2010.1062

Ewers, R. M., Didham, R. K., Fahrig, L., Ferraz, G., Hector, A., Holt, R. D., ... Turner, E. C. (2011). A large-scale forest fragmentation experiment: The Stability of Altered Forest Ecosystems Project. Philosophical Transactions of the Royal Society of London. Series B, Biological Sciences, 366, 3292-3302. https://doi.org/10.1098/ rstb. 2011.0049

Fahmy, M., Ravelomanantsoa, N. A. F., Youssef, S., Hekkala, E., \& Siddall, M. (2019). Biological inventory of Ranomafana National Park tetrapods using leech-derived iDNA. European Journal of Wildlife Research. (in press)

Fiske, I., \& Chandler, R. (2011). unmarked: An R Package for Fitting Hierarchical Models of Wildlife Occurrence and Abundance. Journal of Statistical Software, 43(10), 1-23. http://dx.doi.org/10.18637/jss. v043.i10

Fogden, S. C. L., \& Proctor, J. (1985). Notes on the feeding of land leeches (Haemadipsa zeylanica Moore and H. picta Moore) in Gunung 
Mulu National Park, Sarawak. Biotropica, 17, 172-174. https://doi. org/10.2307/2388511

Gąsiorek, P., \& Różycka, H. (2017). Feeding strategies and competition betweenterrestrialHaemadipsaleeches(Euhirudinea:Arhynchobdellida) in Danum Valley rainforest (Borneo, Sabah). Folia Parasitologica, 64, https://doi.org/10.14411/fp.2017.031

Jucker, T., Hardwick, S. R., Both, S., Elias, D. M. O., Ewers, R. M., Milodowski, D. T., ... Coomes, D. A. (2018). Canopy structure and topography jointly constrain the microclimate of human-modified tropical landscapes. Global Change Biology, 24(11), 1-16. https://doi. org/10.1111/gcb.14415

Kendall, A. (2012). The effect of rainforest modification on two species of South-East Asian terrestrial leeches, Haemadipsa zeylanica and Haemadipsa picta. MSc thesis, Imperial College, London.

Kocher, A., de Thoisy, B., Catzeflis, F., Valière, S., Bañuls, A.-L. L., \& Murienne, J. (2017). iDNA screening: Disease vectors as vertebrate samplers. Molecular Ecology, 38, 42-49. https://doi.org/10.1111/ mec.14362

Laurance, W. F. (2004). Forest-climate interactions in fragmented tropical landscapes. Philosophical Transactions of the Royal Society of London. Series B, Biological Sciences, 359, 345-352. https://doi.org/10.1098/ rstb.2003.1430

Lee, P.-S., Gan, H. M., Clements, G. R., Wilson, J.-J., \& Adamowicz, S. (2016). Field calibration of blowfly-derived DNA against traditional methods for assessing mammal diversity in tropical forests. Genome, 59, 1008-1022. https://doi.org/10.1139/gen-2015-0193

Lutterschmidt, W. I., \& Hutchinson, V. H. (1997). The critical thermal maximum: History and critique. Canadian Journal of Zoology, 75, 1561-1574.

MacKenzie, D. I., Nichols, J. D., Lachman, G. B., Droege, S., Royle, A. A., \& Langtimm, C. A. (2002). Estimating site occupancy rates when detection probabilities are less than one. Ecology, 83, 2248-2255. https ://doi.org/10.1890/0012-9658(2002)083[2248:ESORWD]2.0.CO;2

MacKenzie, D. I., Nichols, J. D., Royle, J. A., Pollock, K. H., Bailey, L., \& Hines, J. E. (2006). Occupancy Estimation and Modeling: Inferring Patterns and Dynamics of Species Occurrence. San Diego, CA: Elsevier, Academic Press

Mann, K. H. (1962). Leeches (Hirudinae): Their structure, physiology, ecology and embryology. Oxford: Pergamon Press.

Nichols, E., Gardner, T. A., Peres, C. A., \& Spector, S. (2009). Co-declining mammals and dung beetles: An impending ecological cascade. Oikos, 118, 481-487. https://doi.org/10.1111/j.1600-0706.2009.17268.x

Niedballa, J., Sollmann, R., bin Mohamed, A., Bender, J., \& Wilting, A. (2015). Defining habitat covariates in camera-trap based occupancy studies. Scientific Reports, 5, 1-10. https://doi.org/10.1038/srep1 7041

R Core Team (2018). R: A language and environment for statistical computing. Vienna, Austria: R Foundation for Statistical Computing. Retrieved from http//www.R-project.org/.

Sawyer, R. (1986). Leech biology and behaviour. New York, NY: Oxford University Press.

Schnell, I. B., Bohmann, K., Schultze, S. E., Richter, S. R., Murray, D. C., Sinding, M.-H. S., ... Gilbert, T. P. (2018). Debugging diversity - A global scale exploration of the potential of terrestrial bloodfeeding leeches as a vertebrate monitoring tool. Molecular Ecology Resources, 1-17, https://doi.org/10.1111/1755-0998.12912

Schnell, I. B., Sollmann, R., Calvignac-Spencer, S., Siddall, M. E., Yu, D. W., Wilting, A., \& Gilbert, M. Thomas. P. (2015). iDNA from terrestrial haematophagous leeches as a wildlife surveying and monitoring tool - Prospects, pitfalls and avenues to be developed. Frontiers in Zoology, 12, 24. https://doi.org/10.1186/s12983-015-0115-z

Schnell, I. B., Thomsen, P. F., Wilkinson, N., Rasmussen, M., Jensen, L. R. D. D., Willerslev, E., ... Gilbert, M. T. (2012). Screening mammal biodiversity using DNA from leeches. Current Biology, 22, R262-R263. https://doi.org/10.1016/j.cub.2012.10.014
Scrimgeour, G. J., Wicklum, D., \& Pruss, S. D. (1998). Selection of an aquatic indicator species to monitor organic contaminants in trophically simple lotic food webs. Archives of Environmental Contamination and Toxicology, 35, 565-572. https://doi.org/10.1007/s0024 49900417

Senior, R. A., Hill, J. K., Benedick, S., \& Edwards, D. P. (2018). Tropical forests are thermally buffered despite intensive selective logging. Global Change Biology, 24, 1267-1278. https://doi.org/10.1111/gcb. 13914

Sket, B., \& Trontelj, P. (2008). Global diversity of leeches (Hirudinea) in freshwater. Hydrobiologia, 595, 129-137. https://doi.org/10.1007/ s10750-007-9010-8

Symonds, M. R. E., \& Moussalli, A. (2011). A brief guide to model selection, multimodel inference and model averaging in behavioural ecology using Akaike's information criterion. Behavioral Ecology and Sociobiology, 65, 13-21. https://doi.org/10.1007/s00265-010-1037-6

Tan, E. (2001). The adaptation of leech (Haemadipsa hainana) to temperature and soil humidity. Acta Ecologica Sinica, 21, 458-461.

Tan, E., \& Liang, C. (2000). Studies on the relationship between the population dynamic of Haemadipsa hainana and climatic factors. Acta Ecologica Sinica, 20, 611-614.

Tan, E., Qian, Y., Zhang, Y., \& Chen, M. (1989). Preliminary study on the ecological distribution of land-leeches in Hainan island. Acta Ecologica Sinica, 9, 384-385.

Tessler, M., Barrio, A., Borda, E., Rood-Goldman, R., Hill, M., \& Siddall, M. E. (2016). Description of a soft-bodied invertebrate with microcomputed tomography and revision of the genus Chtonobdella (Hirudinea: Haemadipsidae). Zoologica Scripta, 45, 552-565. https:// doi.org/10.1111/zsc.12165

Tessler, M., Weiskopf, S. R., Berniker, L., Hersch, R., Mccarthy, K. P., Yu, D. W., ... Siddall, M. E. (2018). Bloodlines: Mammals, leeches, and conservation in southern Asia. Systematics and Biodiversity, 16(5), 488-496.

Timmermann, A., An, S. Il., Kug, J. S., Jin, F. F., Cai, W., Capotondi, A., ... Zhang, X. (2018). El Niño-Southern Oscillation complexity. Nature, 559, 535-545. https://doi.org/10.1038/s41586-018-0252-6

Vad Odgaard, B., \& Rasmussen, P. (2001). The occurrence of egg-cocoons of the leech Piscicola geometra (L.) in recent lake sediments and their relationship with remains of submerged macrophytes. Fundamental and Applied Limnology, 152, 671-686. https://doi.org/10.1127/archiv-hydrobiol/152/2001/671

Weiskopf, S. R., McCarthy, K. P., Tessler, M., Rahman, H. A., McCarthy, J. L., Hersch, R., ... Siddall, M. E. (2017). Using terrestrial haematophagous leeches to enhance tropical biodiversity monitoring programmes in Bangladesh. Journal of Applied Ecology, 55, 2071-2081. https://doi.org/10.1111/1365-2664.13111

Woon, J. S., Boyle, M. J. W., Ewers, R. M., Chung, A., \& Eggleton, P. (2019). Termite environmental tolerances are more linked to desiccation than temperature in modified tropical forests. Insectes Sociaux, 66, 57-64. https://doi.org/10.1007/s00040-018-0664-1

\section{SUPPORTING INFORMATION}

Additional supporting information may be found online in the Supporting Information section at the end of the article.

How to cite this article: Drinkwater R, Williamson J,

Swinfield T, et al. Occurrence of blood-feeding terrestrial leeches (Haemadipsidae) in a degraded forest ecosystem and their potential as ecological indicators. Biotropica. 2019;00:111. https://doi.org/10.1111/btp.12686 